\title{
T Lymphoblastic Lymphoma
}

National Cancer Institute

\section{Source}

National Cancer Institute. T Lymphoblastic Lymphoma. NCI Thesaurus. Code C6919.

The most frequent type of lymphoblastic lymphoma. It comprises approximately $85-90 \%$

of cases. It is more frequently seen in adolescent males. It frequently presents with a

mass lesion in the mediastinum. Pleural effusions are common. (WHO, 2001) 